\title{
Homophobia and Patriarchy in Nicaragua: A Few Ideas to Start a Debate
}

\section{Patrick Welsh}

\begin{abstract}
Reflecting on a 25-year-old study on cultural constructions of same-sex sexual relations between men in Nicaragua, which described a submissive-dominant - or cochón-cochonero-model, this article contrasts this notion with more recent gay identities that have emerged in urban Nicaragua in particular, and which now coexist alongside the more traditional model. Despite many LGBT (lesbian, gay, bisexual, and transgender) groups having emerged in the country, patriarchy is proving resilient and adaptive in surprising ways. Although important victories have been achieved on a global and national scale, culturally and legislatively, in relation to equal rights for LGBT people, this article argues that such advances do not necessarily mean that the intensely andocentric character of patriarchy itself has been significantly challenged or altered. In the struggle for equal rights for all, the models and dynamics of patriarchal power and how they manifest themselves within LGBT organisations, families and relations must also be addressed... and undressed.
\end{abstract}

\section{Homophobia in American Beauty}

Homophobia is one of the central themes of the controversial and award-winning film American Beauty, ${ }^{1}$ released in 1999. In the closing scenes, Frank Fitts, a hyper-macho, retired US Marine Corps colonel, finds himself embroiled in an unprecedented existential crisis, that is, at the same time, a decisive moment of genuine selfdiscovery. For a brief moment, the patriarchal norms that for a lifetime had imprisoned his body, mind and spirit vanish and are vanquished. His authentic self emerges. He kisses another man. Tearful and craving for affection he plants a clumsy and startled kiss on the mouth of the object of his desire - his neighbour Lester. His actions, however, are not reciprocated and his moment of turbulent liberation comes to an abrupt end. In a flash, his covert homoerotic desire, a secret he never wished to discover, is inadvertently laid bare. For the first time in his life he reveals the authentic core of his being to another man. Ironically, within the strict parameters of his own moral codes, that is also the most forbidden and abominable part of himself. ${ }^{2}$ The disclosure of this deeply buried secret terrifies him and fuels the need to lay it to rest instantly, possessing Frank to pull a pistol on the man he has just kissed and cold-bloodedly end Lester's life.

The murder he commits, however, is motivated more by the acute sense of panic that invades him than by the rejection he has just experienced. He realises that the clumsy kiss he has just placed on another man's lips was much more than that. He has also relinquished to another man the power to remove his mask and to oblige him to acknowledge in himself the homosexual desire he has always abhorred in other men.

The interpersonal homophobia and homosexual panic that are portrayed in American Beauty are a crude reality in cultures and subcultures all over the world that stigmatise homosexuality in males (both the 'act' itself and the individuals involved) and that consider it to be immoral, sinful or an illness. The prevailing cultural norms that spawn stereotypes and prejudices vis$\grave{a}$-vis homosexuality in males also generate fear, hatred, discrimination and violence towards those males who do not conform to society's heteronormative and heterosexist vision of patriarchal sexuality. 


\section{Homophobia in Nicaragua}

When I first saw American Beauty, more than ten years ago, it was a criminal offence in Nicaragua, where I live, for two males to have sexual relations. Or more precisely 'sodomy', had been declared illegal in a polemic reform in 1992 that introduced the infamous 'Article 204' into the Nicaraguan penal code (abolished in 2008). ${ }^{3}$ Ironically, compared to its northern neighbours (Honduras, El Salvador and Guatemala) where anti-gay legislation has never existed per se, Nicaragua, in my experience, has a greater level of 'acceptance' of LGBT people, before, during and after '204'. The brutal assassination in Honduras of 74 LGBT people (34 gay men, 35 transwomen and five lesbians) between June 2008 and March 2012, registered by LGBT organisations, and of at least 30 transwomen in Guatemala between 2009 and 2010, is tragic testimony to that (Welsh and Solano 2012).

Whilst official records don't exist, the number of LGBT people in Nicaragua murdered on account of their sexual orientation or gender identity, appears to be much lower. A study carried out in 2011 identified 15 LGBT murders between 1999 and 2011 (Welsh and Altamirano 2012), by no means a definitive number, and in 2012 the Special Procurator for Sexual Diversity in Nicaragua ${ }^{4}$ had documented evidence of five assassinations of LGBT people.

The apparent lower levels of documented hatecrime murders of LGBT people in Nicaragua, compared to other countries in Central America may be linked to the sociocultural transformations that occurred in Nicaragua following the overthrow of the Somoza right-wing military dictatorship in 1979. In their processes of 'democratisation', other countries in the region like Guatemala and El Salvador didn't experience the same definitive break with authoritarian right-wing military structures and values that continued to dominate those societies even after the negotiated peace process of the mid-1990s and which still do to a significant degree until the present day. Furthermore, the increase in hate crimes and murders of LGBT people in Honduras appears to be related to the military coup of 2009 and the political identification of several LGBT leaders and organisations with the Honduran resistance movement. ${ }^{5}$

Another possible explanation for the noticeably fewer murders of LGBT people in Nicaragua may also be related to particular cultural understandings of homosexuality and interpretations of sexual practices, particularly between 'biological men'. The most commonly used word in Nicaragua to describe a homosexual man is cochón. It derives from Náhuatl, the language of the indigenous peoples who inhabited parts of Nicaragua previous to and during the Spanish conquest and also means a coward (Arellano 2006). The fact that its colloquial usage has survived more than 500 years and that it continues to be used widely in Nicaragua strongly implies that cochones were a recognised and visible social group in Náhuatl culture, although little is known of how they were viewed and treated in society. Nowadays, however, cochón is associated with gender identity and expression in biological men that are interpreted culturally as both feminine (to varying degrees) and homosexual and is used derogatorily to demean and stigmatise. It is widely employed in the gender socialisation of boys, to 'correct' them, from a very early age and to ensure that they assimilate those attributes, characteristics, attitudes and behaviours considered socially acceptable as masculine. As such, to brand a boy as a cochón is an act that is simultaneously misogynist and homophobic. It reinforces hegemonic masculinity and the heteronormative and heterosexist attitudes, values and behaviour that are part of it.

\section{Life is hard - homosexuality in Nicaragua in the 1980s}

In his book Life is Hard - Machismo, Danger, and the Intimacy of Power in Nicaragua, written in the early 1990s, Roger Lancaster, an anthropologist from the USA, proposed that modern conceptions and practices of homosexuality that he referred to as 'Anglo-American' and the language used to describe them, were inadequate at that time to describe the cultural specificity of the Nicaraguan homosexual experience that he observed in Nicaragua during the 1980s. ${ }^{6}$

From a cultural point of view, Lancaster argued that the Nicaraguan cochón ${ }^{7}$ and the AngloAmerican 'gay' - both cultural archetypes of sexual identities that transgress heteronormativity - whilst sharing many similarities, also had important differences.

Firstly, Lancaster observed that in the sexual exchanges between two Nicaraguan men (biologically speaking), only the 'passive' 
participant (real or perceived) in anal sex is branded culturally with the label cochón. The other participant, referred to by Lancaster as 'the he-man' and who plays, or is perceived to play an active role in anal sex (i.e. the one who penetrates), is not generally viewed as homosexual and does not usually consider himself to be so.

In Nicaraguan Spanish the 'he-man' who penetrates the cochón is in fact known as the cochonero. The language clearly denotes the relationship between the two and the sexual roles involved that, in theory at least, cannot be altered. Generally, cochoneros do not have sex with each other; neither do cochones. And if they do, and some do, they are likely to keep it quiet. For the cochonero, the experience of anally penetrating another man is assimilated as a source of virility and power. As such, the 'masculinity' of the cochonero remains intact and even reinforced whilst that of the cochón is damaged and diminished. Reflecting ingrained cultural attitudes and beliefs, Lancaster says: 'cochones are therefore feminine men, or more accurately feminized men, not fully male men' (Lancaster 1992: 242).

As such, for a Nicaraguan boy or adolescent growing up, the experience of being branded cochón goes beyond the assimilation of feminine attributes and being called a 'sissy'. It is intrinsically related to the idea of being anally penetrated by another man, leading to the irrecoverable loss of his masculinity in both a symbolic and real way and to social isolation and stigmatisation.

In contrast to the cochón-cochonero model in Nicaragua, in which only the cochón is socially ostracised, Lancaster proposed that, historically, in patriarchal cultures where the AngloAmerican/gay model has developed, both/all participants in sexual activity of any kind between males (and the sexual acts themselves) are condemned and stigmatised from a cultural and religious perspective. Within the AngloAmerican model, oral sex between gays, partly on account of HIV and AIDS, had become a common sexual practice, perhaps more so than anal sex. Knowledge, therefore, of who was penetrating whom (or seen to be) was only one of many possible motives for labelling gay men as 'faggots' or 'queers', and was not in itself a prerequisite for doing so. It is the relationship of a sexual nature between the two males that defines their homosexuality and not the act of penetration itself, as in the case of the cochón.

\section{Power, discrimination and exclusion}

Another element that differentiates the Nicaraguan homosexual experience from the Anglo-American one is the degree of marginalisation faced in relation to heteronormative hegemonic masculinity and the power dynamics that it generates between men. In relation to this, Lancaster argued that the discrimination and rejection experienced by Anglo-American gays, historically, independently of their sexual practices, had led to their exclusion from active participation in the social, economic and political spaces created, controlled and dominated by heterosexual men (or at least to severe limitations). Ironically, he claimed, this was also a key factor in enabling them to create their own autonomous spaces from which to denounce discrimination and violence and to defend their own rights, whilst simultaneously challenging patriarchy. At Lancaster's time of writing, these included the right to equal access to education, health, work, active citizenship and leisure as well as the right to live free from discrimination and violence.

In contrast, as regards the position of the cochón in Nicaragua, Lancaster argued that historically they did not face the same kind of exclusion that their Anglo-American gay counterparts have encountered. Emphasis on the act of anal penetration that goes beyond the symbolic epitomises cochón-cochonero relationships as mutually dependent ones. Primarily of a physical-sexual nature, they frequently also involve affectionate/emotional, social and economic reliance and transactions between the two. These, however, are generally characterised by power inequalities that favour the cochonero and place severe restrictions and limitations on the cochón. The former continues to participate in patriarchal society and enjoy its multiple benefits; the latter endures stigmatisation, marginalisation, abuse and frequent violence. Lancaster notes, however, one without the other ceases to exist - a mutual interdependence that does not occur in the interactions that take place in the same way between gays and heterosexual men in the Anglo-American model.

In this way, the culturally specific experience of homosexuality between men in Nicaragua, as 
represented and symbolised in the cochón-cochonero paradigm, is embedded in heteronormative patriarchy and is an integral component of it. The rigid sexual binarism of the paradigm ensures that in the eyes of society the cochoneros' heteromasculinity remains unquestioned. To penetrate a cochón anally is ample proof that one is NOT a cochón and is a source of affirmation of self-identity and social regard as a 'real man'. Thus it is imperative for cochoneros to subjugate cochones (or at least be seen to do so) and confine them to sociosexual roles that nurture the cochoneros' own sense of manliness and assure their continued access to the privileges and rights of patriarchy. In doing so, they neutralise the capacity of cochones to organise around demands for their own rights and emancipation, whist simultaneously limiting any challenge they may make to patriarchy itself.

\section{Homophobia in present day Nicaragua}

Returning to the question of the particular characteristics and manifestations of homophobia in Nicaragua, the cochón-cochonero paradigm would suggest that it has been substantially different from the viscerally violent model presented in the film American Beauty. Cochones - historically the visible and stigmatised face of sexual practices between men - are undoubtedly subjected to vicious ridicule and constant derision within families and communities, as well as discrimination and violence. Despite the intensity of Nicaraguan 'machismo', however, cultural attitudes to sexuality in general vary and in many settings cochones experience minimal levels of 'tolerance' and often are even supported and protected by close friends and occasionally family members. Their 'acceptance', however, is intrinsically linked to their willingness to conform to the role that has been socially prescribed to them and that demands of them passive submission to and collusion with the very patriarchal system that subjugates and controls them. In doing so their visibility, in the words of Lancaster as 'feminised men', serves as a deterrent to other men warning them not to digress (publicly at least) from the cultural norms of hegemonic masculinity, whilst simultaneously contributing to the perpetuation of patriarchal norms.

Homophobia in Nicaragua is first and foremost related to the fear of being labelled cochón and the implications inherent in that. It is internalised through processes of gender socialisation that drive boys and men to express constantly that they are 'real men' by proving that they are neither women nor cochones. Consequently, to achieve that, patriarchal attitudes, values and behaviour are reinforced, which in turn contribute to discrimination and violence against women and girls and the perpetuation of patriarchy.

\section{Lancaster put it this way:}

It is not that homophobia is more intense in a culture of machismo, but that it is a different sort of thing altogether. Indeed, the word homophobia meaning a fear of homosexuals or homosexual intercourse, is quite inappropriate in a milieu where unlabeled men desire and actively seek intercourse with labeled men. An altogether different word is necessary to identify the praxis implicit in machismo, whereby men may simultaneously use, fear being used by, and stigmatize other men (Lancaster 1992: 269).

Whatever that word may be, its absence from the Nicaraguan vernacular does not mean that cochones do not suffer the consequences of homophobia and transphobia that result from heteronormative and heterosexist gender norms and practices that view them as inferior and 'abnormal'. All too often they bear the brunt of abusive insults, discrimination and violent acts that limit their access to education, health services and work and that are a constant threat to their mental, physical and sexual health, human dignity and right to life.

\section{The evolution of LGBT identities, organisation and rights in Nicaragua}

In recent years in Nicaragua, and particularly since the decriminalisation of homosexuality in 2008 , there has been a proliferation of groups and organisations that are working from a human rights perspective and that self-identify as LGBT. At the same time, in contemporary Nicaragua at least, the autochthonous cochón-cochonero paradigm has never really existed as an exclusive model of homosexuality between men. During the 1980s, for example, in the midst of the Sandinista Revolution, a 'gay' collective emerged in Managua that brought together a group of young revolutionaries who self-identified mostly as lesbians and gays. ${ }^{8}$ The latter category, however, integrated at least two sub-groups of homosexual men - those who had 
been culturally labelled as cochones and those whose self-identification was as 'gays', within a modern conceptualisation of the term. To some degree, the distinction between the two subgroups was also related to issues of social class, formal educational achievements, the influence of religion, economic capacity, access to other cultures and urban/rural origins.

Also, during the 1990s, after the war ended, large numbers of Nicaraguans who lived in other countries such as the USA and Costa Rica, including LGBT people, returned to Nicaragua, bringing with them other visions and experiences of diverse sexualities. Simultaneously, between 1992 and 2008, in the face of the criminalisation of homosexuality, several NGOs working on gender, HIV prevention, and sexual and reproductive health and rights (SRHR) $)^{9}$ openly and defiantly worked on LGBT issues, whilst offering safe spaces for LGBT people to meet and take part in processes that contributed to their personal growth and political maturity. Also, the rapid globalisation of mass communications, especially TV, cinema and internet, enabled access to and dissemination of modern concepts and practices of sexuality and the opening-up of new spaces for discussion, and debate on sexual orientations and gender identities in Nicaragua, in an unprecedented way.

Whilst the cochón-cochonero model may continue to be more prevalent in rural and semi-rural areas and the LGBT one in urban settings, the division is not always a clear and simple one. Many gays and transwomen in cities and towns experience abuse and discrimination at the hands, for example, of medical professionals and police officers whose expression of homo/transphobia derives from the cultural representation of cochón, implying a lack of informed awareness of diverse sexual orientations and gender identities. Also, some LGBT organisations (particularly transgender) have carried out important processes of consciousness-raising and personal growth in semi-rural areas with self-identifying gays and transwomen who previously in their own communities would have been referred to and treated as cochones. Indeed, for many people in Nicaragua, 'gay' is often synonymous with cochón in that it conjures up an image of feminised men, linked to the erroneous belief that all 'gays' in effect want to become women.
Currently, the simultaneous presence in Nicaragua of both modern gays (Lancaster's 'Anglo American' model of homosexuality) and the autochthonous cochón-cochonero paradigm is indicative of a process of cultural syncretism that in itself has implications in relation to how homophobia is expressed, to whom it is directed, to what degree it affects LGBT people and with what consequences. A study on hate crimes against LGBT people in Nicaragua in 2011 identified 15 murders committed between 1999 and 2010; seven of those murdered were gays, seven were transwomen and one was lesbian. ${ }^{10} \mathrm{In}$ its analysis of those murders and of other hate crimes committed in the same period (assaults, attacks, etc.) the study highlighted that transwomen were more vulnerable to hatemotivated crimes in public places (parks, bars, streets, etc.) whereas gay men were more at risk in their own homes. Also, many of the crimes committed against gay men were linked to clandestine relationships that involved psychological/emotional manipulation and economic extortion (Welsh and Altamirano 2012).

It would be tempting to conclude that the term cochón is in fact synonymous with 'transwomen'. That, however, is not necessarily the case. Selfidentifying transwomen in Nicaragua have undergone a conscious process of personal transition and social transgression that involves choices related to their own gender identity and expression and sexual orientation. Cochón is merely a label used to stigmatise 'feminised men' and for social control. In all likelihood, many of the self-identifying gay men included in the aforementioned study would also have been branded as cochones, especially those whose gender expression (or elements of it) is culturally interpreted as feminine.

Nowadays, it is also probable that many biological men who have previously been labelled culturally as cochones would self-identity as transwomen, but the term itself, from a strictly cultural perspective, is a much wider one. It is in fact related to any combination of gender identity, gender expression and sexual orientation that breaks the heteronormative and heterosexist mould of what biological men should look like, and in relation to whom and how they should love. In practice, however, the more feminised a biological man's presentation is, the more intense and destructive the discrimination and violence experienced. 


\section{Access to rights, homophobia, and patriarchy}

Since Lancaster's sexual archaeology of the Nicaraguan cochón-cochonero paradigm almost a quarter of a century ago, significant advances have been achieved, culturally and legislatively, on a global scale in relation to equal rights for LGBT people that include access to health and education, decriminalisation, legal recognition and protection, civil partnerships, access to adoption, and marriage equality in at least 15 countries.

This would seem to imply that LGBT activists and movements have had considerable success in challenging the heteronormative and heterosexist attitudes and beliefs ingrained in many cultures.

It does not necessarily mean, however, that the intensely andocentric character of patriarchy itself has been significantly challenged or altered. For many gay men, perhaps, it simply translates into being able to enjoy the benefits of patriarchy (some at least, if not all of them) on an 'equal basis', that their heterosexual counterparts have had for centuries. In fact, their access to and inclusion into formerly

\section{Notes}

1 For more information on American Beauty see: http://en.wikipedia.org/wiki/American_ Beauty_(film).

2 This ten-minute collage of scenes from American Beauty follows the evolution of Frank Fitts' homophobic and self-loathing character, leading up to the fateful kiss: www.youtube.com/ watch?v=8QIqX_UDoIg.

3 At the time of the introduction of Article 204 in 1992, concerted efforts were made nationally and internationally for its repeal (with the support of Amnesty International and the United Nations) but without success. The elimination of '204' in 2008 came about as a result of the introduction of a brand new penal code and not directly in response to the demands of LGBT organisations. It also included two Articles that address discrimination on the basis of sexual orientation (Articles 36 and 315). Ironically, within the same new penal code, abortion for medical reason was criminalised and many feminists and human rights activists believe that the elimination of Article 204 was, in a sense, a political decision to sow divisions between the women's movement and the emerging LGBT movement.

4 In a surprise development on 30 November 2009 the Procurator for Human Rights (State hetero-exclusive spaces, public and political organisations and social institutions may just be a manoeuvre to perpetuate patriarchy itself.

In Nicaragua, certainly, the urgent need to eliminate discrimination, violence and hate crimes against LGBT people is intrinsically linked to the recognition of homo/trans/lesbophobia as a major pillar that helps sustain patriarchy. Their deconstruction must not only entail the eradication of personal 'phobias' but also the challenging and transformation of those cultural, social, economic, religious and political institutions and structures that reproduce and reinforce andocentric, heteronormative and heterosexist value systems and practices that oppress and marginalise LGBT people and can render them expendable. In the struggle to have the same rights enjoyed by straight people, the models and dynamics of patriarchal power itself and how they manifest themselves within LGBT organisations, families and relations must also be addressed... and undressed.

Ombudsman) appointed a Special Procurator for Sexual Diversity in Nicaragua, the first of its kind in Latin America and the Caribbean. The special procurator's principal role is to monitor state and government entities to ensure that they respect the human rights of the LGBT community in Nicaragua. Whilst generally welcomed in political and development circles, little state funding has been made available and the future of the post depends solely on the will of the incumbent Procurator for Human Rights. The election of a new Procurator could see the disappearance of the Special Procurator for Sexual Diversity position. Also, some critics (political opposition and feminists) claim that the creation of the post serves the political interests of the Sandinista governing party in its attempt to monitor and control the emerging LGBT groups and whose international reputation on women's rights had been severely damaged with the criminalisation of abortion for medical reason in 2008.

5 For more information see:

http://resistediverso.blogspot.com/ and www.facebook.com/Movimiento.de.Diversidad. en.Resistencia.

6 The reflections and analysis in this article related to Lancaster's book Life is Hard stem 
from my own reading and interpretations, in particular of the final chapter of the book entitled 'Subject Honor, Object Shame' (Lancaster 1992: 235-78).

7 Cochón in Nicaraguan Spanish is generally used in a derogatory way and can be deeply offensive and insulting. In this article the word is used, sociologically, in the same way in which Lancaster used it in his book. It refers to the particular sociocultural construction and sexual identification of a minority of Nicaraguan men who are culturally labelled as cochones on account of perceived femininity in their gender expression. Its use here, far from having derogatory connotations, seeks to illuminate the inherent differences in the two cultural models of homosexuality being examined.

8 In 1991, Lucinda Broadbent, a Scottish filmmaker, made a documentary on this gay-lesbian collective. Entitled Sex and the Sandinistas it explores the hidden world of lesbian and gay culture in Managua - from safe sex demonstrations to drag shows, from lesbian love poetry to debates about butch/femme role-playing, and it includes a tribute to Nicaragua's homosexual indigenous

\section{Bibliography}

Amnistía Internacional (2006) Lesbianas, Gays, Bisexuales y Personas Transgénero (LGBT) en Peligro en Nicaragua, Londres: Amnistía Internacional, www.amnesty.org/es/library/asset/AMR43/ 003/1994/es/f664796f-ebe9-11dd-8cf149437baee 106/amr430031994es.html (accessed 14 November 2013)

Amnistía Internacional (2004) Nicaragua: El Artículo 204 y la Legalización de la Represión, Londres: Amnistía Internacional, www.amnesty.org/es/ library/asset/AMR43/003 1994/en/f5e ldbdaebe9-1 1dd-8cf1-49437baee 106/amr43003 1994es.pdf (accessed 14 November 2013)

Arellano,J.E. (2006) 'Del léxico sexual en Nicaragua', La Prensa, 8 October, http://archivo.laprensa.com.ni/archivo/2006/ octubre/08/noticias/opinion/147955_print.shtml (accessed 12 November 2013)

Grupo Estratégico por los Derechos Humanos de la Diversidad Sexual (2010) Una Mirada a la Diversidad Sexual en Nicaragua, 1st edition, ancestors. Without assuming any prior knowledge of Nicaraguan history, the film brings to life the extraordinary and valuable experience of lesbians and gays coming out in the whirlwind of a Latin American revolution (www.wmm.com/filmcatalog/pages/c27.shtml). Copies of Sex and the Sandinistas can be purchased directly from Lucinda Broadbent who is current director and executive producer of Media Co-Op based in Glasgow, Scotland.

9 These include but are not limited to Puntos de Encuentro, Si Mujer, Grupo Venancia, Association of Men Against Violence as well as many feminist collectives and women's groups in different parts of the country.

10 Only one hate crime against lesbians was documented in the study that as well as indepth interviews with LGBT leaders in different parts of Nicaragua also carried out an exhaustive review of reports in national newspapers going back to the late 1990s. The study suggested that this was probably related to the general invisibility of lesbians in society and to issues related to violence against women, recommending future research on lesbophobia and violence against and between lesbians.

GEDDS Managua: www.prevensida.org.ni/ index.php?option $=$ com_k2\&view $=$ item $\&$ task $=$ download $\& i d=10 \overline{7} \&$ Itemid $=4($ accessed 14 November 2013)

Lancaster, Roger N. (1992) Life is Hard, Berkeley CA: University of California Press

Nicaragua (2008) Ley No. 641 Código Penal, Managua, www.ub.edu/dpenal/CP Nicaragua.pdf (accessed 14 November 2013)

Welsh, P. (2000) 'Homofobia y Patriarcado en Nicaragua', El Nuevo Diario, 28 July, http://archivo.elnuevodiario.com.ni/2000/julio/ 28-julio-2000/sexualidad/sexualidad 1.html (accessed 14 November 2013)

Welsh, P. and Altamirano, A. (2012) Diagnóstico sobre Discriminación y Crímenes de Odio en Contra de las Personas de la Diversidad Sexual en Nicaragua, Nicaragua: CEJIL/Hivos

Welsh, P. and Solano, A.C. (2012) Evaluative Study of HIVOS'LGBT Programme in Costa Rica, Nicaragua, El Salvador, Guatemala and Honduras, San José, Costa Rica: Hivos 